\title{
CLINICAL RECORDS
}

7. Under conditions of movement of troops in a theater of operations, follow-up examinations may not always be possible at the scheduled time. Adequate check-ups will sometimes depend on the understanding and knowledge which the soldier has about this infection. At the time the diagnosis of syphilis is established, the medical officer responsible has an unparalleled responsibility and opportunity to acquaint the patient with the nature of his disease, his chance of cure by intensive therapy, the importance of follow-up serological and spinal fluid tests, and the importance of reporting any lesion suggesting mucocutaneous relapse. The Supplementary Record of Treatment, ETOUSA MD Form 313, will be filled out and given to each patient, and the times for further laboratory or clinical examinations indicated thereon. This is in addition to the Syphilis Register (Form 78).

8. Treatment of patients with coincident gonorrhea or chancroid and early syphilis. Penicillin is the drug of choice for the treatment of gonorrhea in such patients. However, if penicillin is not available for this purpose, there has been no indication that patients in good general physical condition will not ordinarily tolerate combined sulfonamide and intensive Mapharsen therapy. In such patients, sulfadiazine is the sulfonamide of choice, because of its lower sensitizing properties.

\section{CLINICAL RECORDS}

\section{A CASE OF GONOCOCCAL URETHRITIS IN THE MALE, WITH STRICTURE, PERI-URETHRAL STONE AND CORPUS SPONGIOSUM FISTULA}

In October 1943, a tall powerful Thames bargeman, 65 years old and a bachelor, was sent up to hospital for "carcinoma of penis". He presented a swollen convoluted glans penis jutting out from the swollen convoluted prepuce of an old-standing paraphimosis.

Sinuses opened in the deep furrows between the convolutions of the glans on both sides, while on the left lay a larger whiter and very hard convolution of apparently fibrosed corpus spongiosum, the distal slope of which ended in a shallow furrow holding the small opening of a sinus. A probe passed along this sinus struck on stone and, on squeezing the glans, pus sprang from every furrow.

The displaced meatus led to a stricture, which admitted only a probe, situated at level of dorsal sulcus.

Fig. 1.-Stone in glans penis shown by $x$-ray examination.

The whole stank with the foul odour of infected urine and, on micturition,
rine escaped from the glans in thin discrete spouts on all sides, with one bigger frontal spout from the meatus.

$\mathrm{X}$-ray (Fig. 1) revealed a stone underneath the white hard convolution of glans on left side, thus conforming to the discovery made by probing.

Microscopical examination of the pus showed gonococcus, coliform bacterium, streptococcus, diphtheroid. Wassermann and Kahn blood tests (repeated) were strongly positive. No other evidence of syphilis was detected.

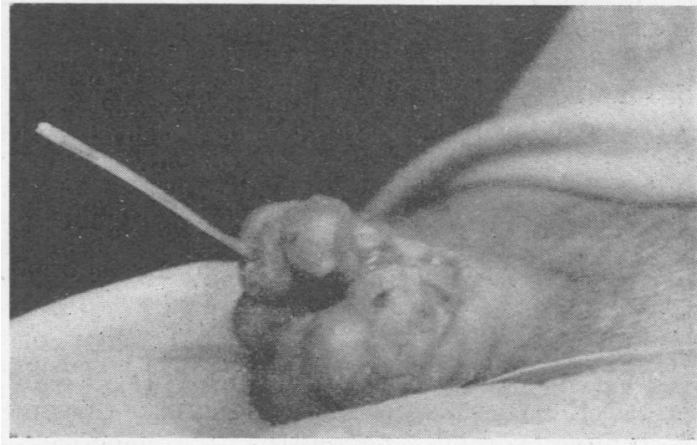

Fig. 2.-Probe in meatus. 
All attempts to elicit a history failed. The patient always foiled every question by his silence.

Under pentothal anaesthesia the stone was removed from a cavity (see Fig. 2), with smooth dense avascular walls, at far end of which was an opening into urethra, but this apparently was too small for repassage of the stone which measured about $\frac{1}{3}$ by $\frac{1}{4}$ inch. One assumes that the stone had reached its peri-urethral position by ulceration behind an anterior urethral stricture, and probably was aided in its passage by the formation of a peri-urethral abscess into which it passed, and from which the present sinuses burrowed through the glans to the surface. The sinuses now passed through a corpus spongiosum much fibrosed and almost avascular-clearly the end of a long-treasured process. In addition to treatment of the bacterial infection and dilatation of the stricture, the patient was given anti-syphilis treatment, with little or no effect except to turn him gonococcus free. After 10 months' dumb endurance of these efforts, which had made little change in the " sprinkler" "effect on micturition, he suddenly spoke up for amputation. Amputated.

V.D. Clinic,

Seamen's (Albert Dock) Hospital

H. M. HANSCHELL, D.S.C., M.R.C.S.

\section{(1) TUBERCULOUS EPIDIDYMITIS ASSOCIATED WITH OR REACTIVATED BY ACUTE GONORRHOEA}

The following case, which was seen in the clinic during the past year, seems to be of interest because of the apparent rarity of the condition.

\section{Case history}

A foreign seaman aged 23 years attended the clinic on 1st November 1943, complaining that he had had a discharge for fourteen days and a swelling of his left testicle for seven days.

On examination, he showed a purulent urethral discharge and marked urinary haze. Smears showed the presence of much pus and gonococci. There was an acute left-sided epididymitis and bilateral prostato-vesiculitis. The right testis and epididymis had been removed in boyhood; the possible significance of this operation was not realized at the time. The gonococcal complement fixation test was positive; the Wassermann reaction was negative.

Treatment with $\mathbf{2 0}$ grammes of sulphathiazole in four days, combined with gentle local irrigation, cleared the urinary haze and produced a temporary cessation of the urethral discharge (until 16th November, when pus and gonococci were again present in the smears) but effected no improvement in the condition of the epididymis, prostate and seminal vesicles. In accordance with the clinic routine a course of detoxicated gonococcal vaccine was given. This was followed by a further $\mathbf{4 0}$ grammes of sulphathiazole in eight days (2nd-10th December) but without success; the urethral discharge persisted with pus and gonococci still present; no clinical improvement was observed in the state of the epididymis, prostate and vesicles.

In view of the tendency to relapse, hyperpyrexial treatment was decided on ; three fever sessions, each of 8 hours at $106^{\circ}-106 \cdot 8^{\circ} \mathrm{F}$., were induced between 29 th December and 27 th January. There was slight clinical improvement after the first and second, followed by relapse ; after the third fever there was no further urethral discharge nor any further bacteriological evidence of gonorrhoea. The left epididymitis and bilateral prostatitis and vesiculitis persisted, although the real cause was unsuspected until, on 9th March, a cold abscess appeared at the lower pole of the left epididymis. This was at first regarded as a residual condition and it was aspirated. Smears of the aspirated material showed pus cells but no gonococci; a spread stained by the Ziehl-Neelsen method showed tubercle bacilli, a finding which was subsequently confirmed by the hospital bacteriologist. Tubercle bacilli were not found in the urine, but $x$-ray examination of the chest showed evidence of pulmonary tuberculosis. Multiple chronic sinuses developed in the scrotum and a tuberculous ulcer on the glans penis. Surgical intervention was advised but refused. The patient was then transferred to a sanatorium.

\section{Commentary}

I have been unable to find any record of a similar case in the literature, although, among the various predisposing causes of genito-urinary tuberculosis, gonorrhoea is frequently mentioned as being the chief. Thus, Hamilton Bailey writes that examples of gonorrhoeal infection followed by tuberculous epididymitis are few 